\title{
AlN Precipitates and Microstructure in Non-oriented Electrical Steels Produced by Twin-roll Casting Process
}

Ting $Z H A N G^{1)}$, Xiaoming ZHANG ${ }^{1 \dagger \dagger}$, Zhiyuan $G U O^{2)}$, Yuqian $W A N G^{1)}$, Chenggang $L I^{1)}$ and Liangyun $\left.L A N^{1}\right)$

1) The State Key Laboratory of Rolling and Automation, Northeastern University, Shenyang 110819, China

2) Laiwu Iron and Steel Group Co. Ltd, Laiwu 271104, China

[Manuscript received 22 November 2012, in revised form 16 April 2013]

(C) The Chinese Society for Metals and Springer-Verlag Berlin Heidelberg

\begin{abstract}
Aluminum nitride (AIN) precipitates and microstructure of $4 \mathrm{wt} . \%(\mathrm{Si}+\mathrm{Al})$ non-oriented electrical steel were investigated. The $2.0 \mathrm{~mm}$ thick cast strips with three different silicon/aluminum $(\mathrm{Si} / \mathrm{Al})$ ratios were produced by twin-roll casting process, then the strips were reheated, warm rolled, cold rolled and annealed. The microstructure and AIN precipitates were characterized using optical microscopy, scanning electron microscopy and transmission electron microscopy. The results showed that with the increase of Si/Al ratio, on the one hand, the casting microstructure changed from columnar grains to equiaxed grains, and the uniformity of annealed microstructure was improved; On the other hand, the number of AIN precipitates in cast strips reduced meanwhile the distribution became dispersed. By the reheat treatment, the size and distribution of the AIN precipitates can be changed. Moreover, the grain size of the annealed strips is in the range of 20-50 $\mu \mathrm{m}$, at the same time, many AIN precipitates were located at grain boundaries. Therefore, controlling the $\mathrm{Si} / \mathrm{Al}$ ratio is a simple method to obtain desired microstructure. Then AIN precipitates in non-oriented electrical steel prepared by twin-roll casting process hinder markedly the recrystallized grains growth. A compatible reheat treatment can be an approach worth exploring to control the behavior of AIN precipitates.
\end{abstract}

KEY WORDS: Twin-roll casting; Non-oriented electrical steels; Microstructure;

Aluminum nitride

\section{Introduction}

High-grade non-oriented electrical steel is mainly used in high capacity, middle and large electric motor due to its low core less ${ }^{[1,2]}$. Usually, by increasing alloy elements content, the magnetic properties can be improved, but the hardness and the brittleness are increased. In particular, the Si content over 3.25 wt.\% or the $(\mathrm{Si}+\mathrm{Al})$ content over $4 \mathrm{wt. \%}$, the cold rolling of the steel becomes difficult ${ }^{[3]}$. For this reason, the rolling yield by traditional hot and cold roll procedures is low. The twin-roll casting process, which is a developed technology with many advantages ${ }^{[4-7]}$, is employed to produce nonoriented electrical steels. Especially for high-grade

\footnotetext{
† Corresponding author. Prof., Ph.D.; Tel: $\quad+86$ 13840015633; Fax: +86 24 23906472; E-mail address: zhangxm@ral.neu.edu.cn (Xiaoming ZHANG)
}

DOI: $10.1007 / \mathrm{s} 40195-012-0221-2$ non-oriented electrical steels, its superiority exists not only in energy-saving and low cost, but also better in magnetic properties and workability.

There are important relationships between the process, microstructure and performance of materials. Improvements in the properties of materials have led to a wide range of research about how to control the microstructure of the polycrystalline materials ${ }^{[8]}$. The magnetic properties of non-oriented electrical steel are strongly dependent on recrystallized grain size ${ }^{[9,10]}$. The final microstructure of this steel is obviously affected by the thermo-mechanical process, the thermal treatment and the initial microstructure ${ }^{[11-13]}$. Besides, the precipitate controlling is one of the most important technologies in electrical steel-making process. Many precipitates in electrical steels are usually in the size range $10-400 \mathrm{~nm}$. Such particles can influence the magnetic properties of the steels. In the case of the steels with 1.0 wt.\% Al, the harmless AlN 
Table 1 Chemical composition of the steels (wt.\%)

\begin{tabular}{ccccccccc}
\hline Sample & $\mathrm{Si}$ & $\mathrm{Al}$ & $\mathrm{Mn}$ & $\mathrm{P}$ & $\mathrm{S}$ & $\mathrm{C}$ & $\mathrm{N}$ & $\mathrm{Fe}$ \\
\hline Designed A & 3 & 1 & 0.2 & $\leq 0.02$ & $\leq 0.005$ & $\leq 0.005$ & $\leq 0.005$ & Bal. \\
Tested A & 3.015 & 1.037 & 0.19 & 0.0066 & 0.003 & 0.005 & 0.0045 & Bal. \\
Designed B & 3.3 & 0.7 & 0.2 & $\leq 0.02$ & $\leq 0.005$ & $\leq 0.005$ & $\leq 0.005$ & Bal. \\
Tested B & 3.375 & 0.722 & 0.185 & 0.006 & 0.005 & 0.0049 & 0.0036 & Bal. \\
Designed C & 3.6 & 0.4 & 0.2 & $\leq 0.02$ & $\leq 0.005$ & $\leq 0.005$ & $\leq 0.005$ & Bal. \\
Tested C & 3.594 & 0.409 & 0.225 & 0.0094 & 0.004 & 0.0026 & 0.0048 & Bal. \\
\hline
\end{tabular}

$(>1.0 \mu \mathrm{m})$ has been observed ${ }^{[14,15]}$.

In recent years, some studies reported on preparing electrical steel by twin-roll casting process, for example, Liu et al. ${ }^{[16]}$ tracked the solidification structure and crystallographic texture of the strip casting 3 wt.\% Si non-oriented silicon steel. Landgraf et al. ${ }^{[17]}$ studied the magnetic properties of silicon steel with as-cast columnar structure. But none of these work focused on the AlN precipitates and the microstructure of 4 wt.\% ( $\mathrm{Si}+\mathrm{Al})$ non-oriented electrical steel strips prepared by twin-roll casting process.

In the present study, three 4 wt.\% ( $\mathrm{Si}+\mathrm{Al})$ nonoriented electrical steels with different $\mathrm{Si} / \mathrm{Al}$ ratios were prepared by twin-roll casting process, then rolled and treated at different annealing processes. The influence of the $\mathrm{Si} / \mathrm{Al}$ ratio on the microstructure and AlN precipitates has been investigated to understand microscopic characteristics. In addition, we have done some exploratory research on the influence of reheat treatment on AlN precipitate behavior.

\section{Experimental}

The materials used in the current work are Fe4 wt.\% $(\mathrm{Si}+\mathrm{Al})$ alloys with three different $\mathrm{Si} / \mathrm{Al}$ ratios. The raw materials were melted in a vacuum furnace and refined until the content of sulfur, oxygen, nitrogen, and other alloying elements in the steel were maintained at the design level. The chemical composition of the steels designed and tested is shown in Table 1. The content of impurity elements was controlled within the chemical analysis standard. And minor compositional variation resulted in a small difference in the rate of recovery, recrystallisation and grain growth but no difference in the distribution of the nitride precipitates ${ }^{[18]}$. When the superheat degree was $20^{\circ} \mathrm{C}$, the melt was poured. Subsequently the strip was cooled in air to the room temperature. The following process is shown in Fig. 1. The $\mathrm{HCl}$ solution was used to clean the oxide scale of steel, and acid pickling temperature was $50-60{ }^{\circ} \mathrm{C}$ with the duration time of $5 \mathrm{~min}$.

The size of the specimens is $12 \mathrm{~mm} \times 8 \mathrm{~mm}$ (longitudinal direction $\times$ cross direction). The longitudinal section microstructure of the specimens was observed after whetting, polishing and etching. The corrosive liquid is the alcohol solution containing $4 \%$ nitric acid (volume fraction). The erosion time was $40 \mathrm{~s}$. The op-

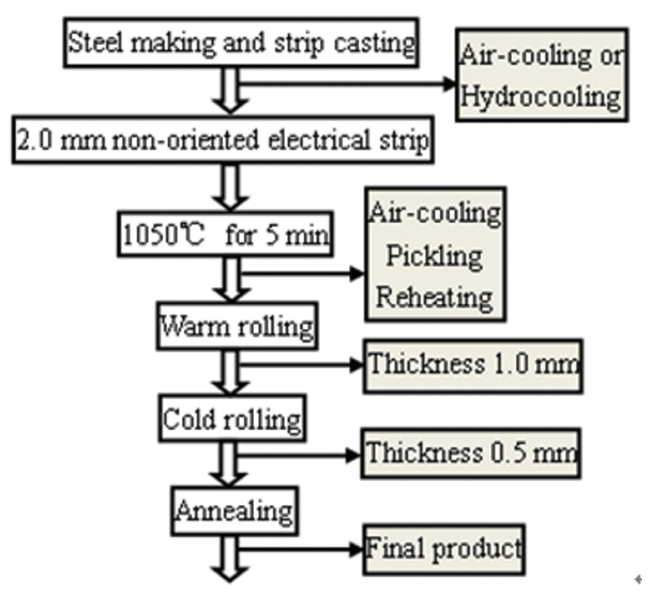

Fig. 1 Process flow diagram

tical microscope (OM), scanning electron microscope (SEM) and transmission electron microscope (TEM) were used to characterize the microstructure and AlN precipitates.

\section{Results and Discussion}

\subsection{AlN precipitates and microstructures in the cast strips}

Fig. 2 shows AlN precipitates and casting microstructure of the non-oriented electrical steel strips. Fig. 3 shows the EDX analysis of the precipitates from marked by numbers 1, 2 and 3 shown in Fig. 2. The observation illustrates that there exists an important relationship among chemical composition, casting microstructure and morphology distribution of AlN precipitates. In steel A, the microstructure, which with average grain diameter of $225 \mu \mathrm{m}$, is composed of $80 \%$ columnar grains and $20 \%$ equiaxed grains. In steel $\mathrm{C}$, the average grain diameter is about $210 \mu \mathrm{m}$. As shown in Fig. 2(c), the microstructure is the equiaxed grains which are distributed on the whole longitudinal section. The microstructure of steel B consists of a small amount of equiaxed grains and a large number of the grains like a polygon oval in shape. The average grain diameter is $173 \mu \mathrm{m}$. That is to say, with the increase of $\mathrm{Si} / \mathrm{Al}$ ratio, the percent of columnar grains decreases. Meanwhile, AlN precipitates presented a clear trend in the distribution and quantity. In steel $\mathrm{A}$, it was not only a very huge number but also chain- 

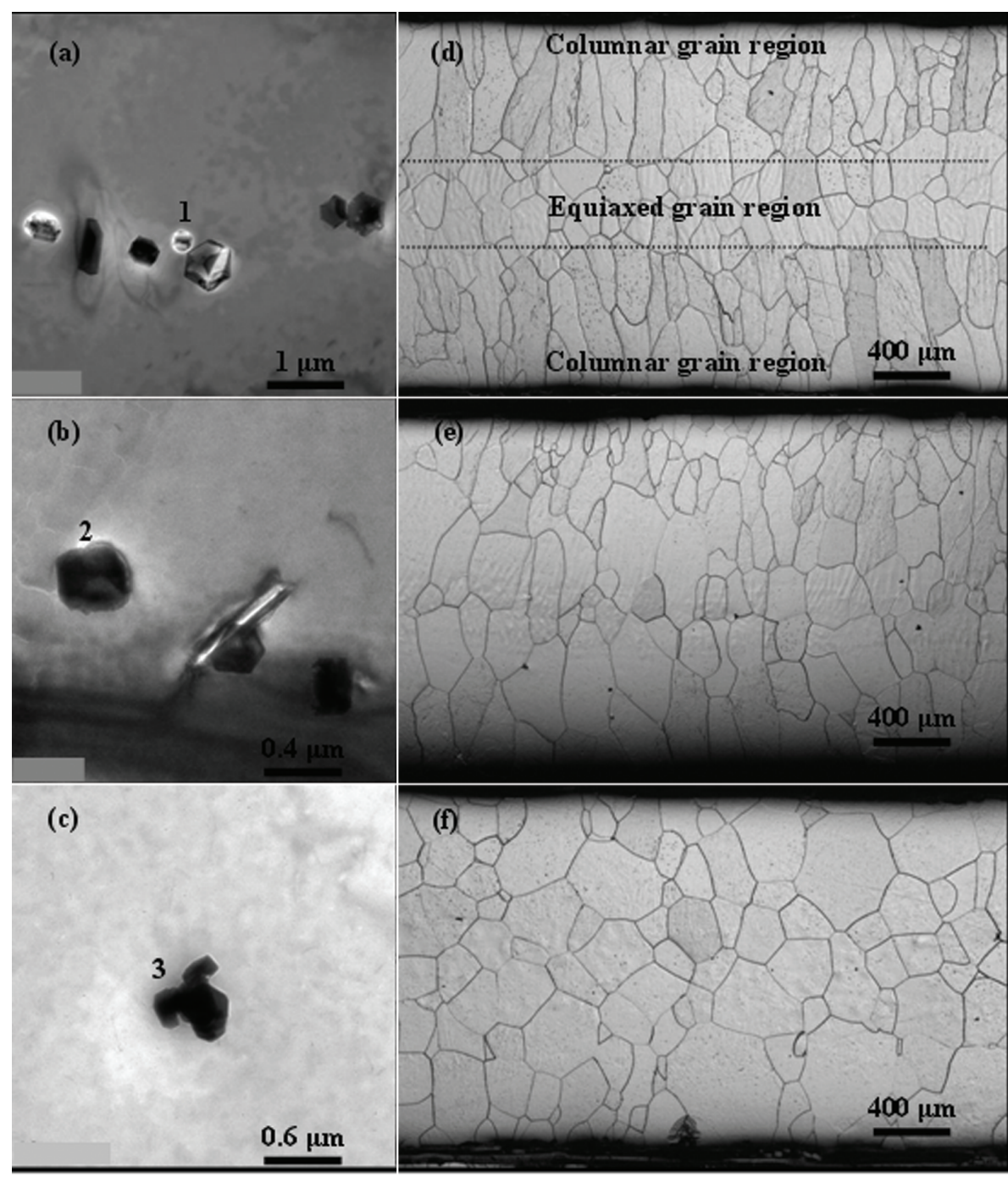

Fig. 2 TEM images of the precipitates and microstructures of the casting strips: (a, d) steel A; (b, e) steel B; (c, f) steel C
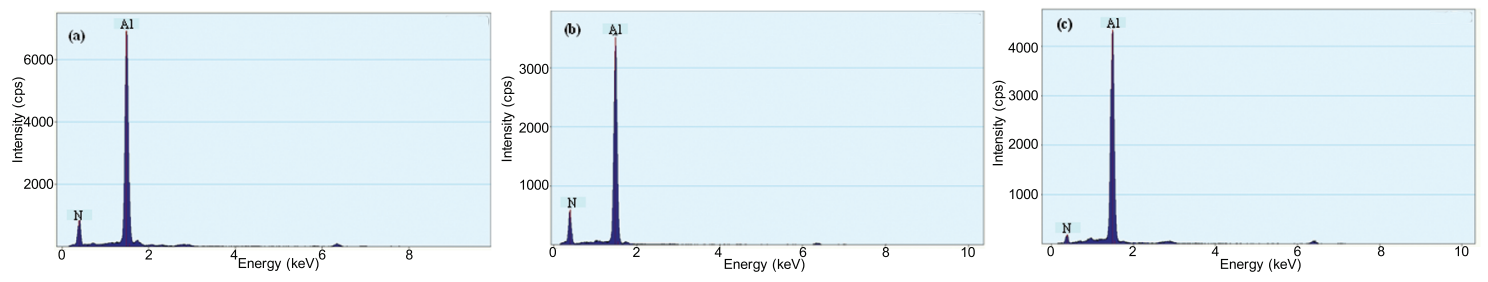

Fig. 3 EDX analysis of the precipitates corresponding to the Fig. 2: (a) 1 ; (b) 2 ; (c) 3

type distribution. The distance between every two adjacent precipitates was about once or twice as large as their width. With the increase of $\mathrm{Si} / \mathrm{Al}$ ratio, the number decreases and the distribution becomes dispersive. By contrast, in steel $\mathrm{C}$, the second phases are randomly dispersed. The common feature of second phase in the three steels is that the maximum size of most precipitates (width) is about $500 \mathrm{~nm}$.

After leaving the casting rollers, the non-oriented electrical steel strips were cooled, which accompanied the nucleation and growth of the grain. The high content of aluminum promotes the formation of the columnar grains. The reason is that the latent heat and the thermal conductivity of $\mathrm{Al}$ are higher than those of $\mathrm{Si}$, as a result the higher temperature gradient forms in steel A, which is one major cause of the columnar grain structure formation. So in steel A, there are a lot of columnar grains, but hardly exist in steel C. The columnar structure, which is good for the magnetic properties, often is $\{100\}$ orientation. In addition, when the content of $\mathrm{Al}$ reduces, the number of AlN decreases certainly. During the cooling process of the molten steel, under the condition of fluctuation of energy and chemical composition, a large number 


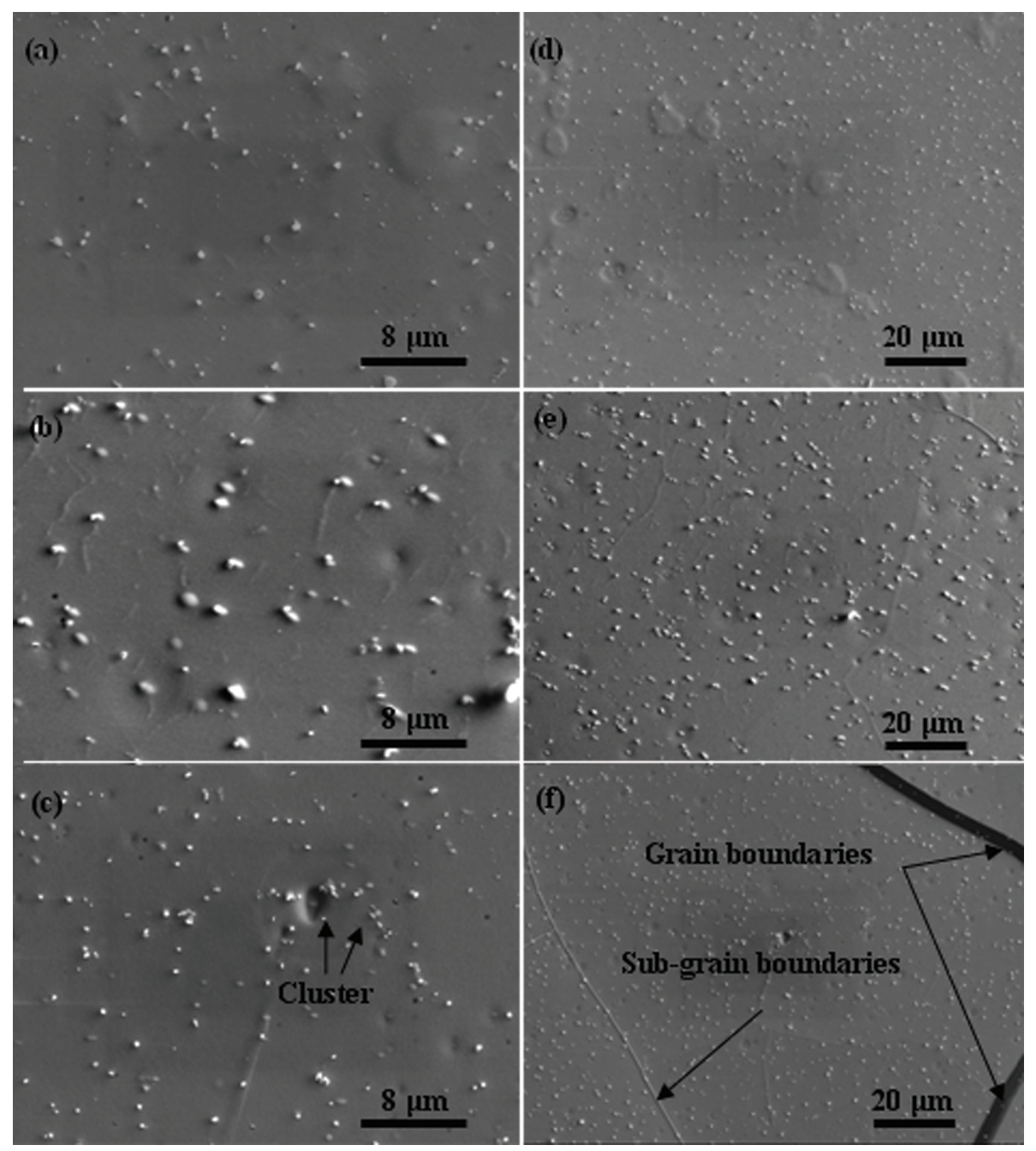

Fig. 4 SEM micrographs of AlN precipitate at $1050{ }^{\circ} \mathrm{C}$ for different holding times: (a, d) 6 min; (b, e) 10 min; (c, f) $15 \mathrm{~min}$

of second phases preferentially nucleate in high energy zone such as sub-boundaries. Therefore, when a huge amount of AlN precipitates occur, they usually appear in chain-like distribution.

\subsection{Influence of reheat treatment system on AlN pre- cipitates}

Non-oriented electrical steel cast strips (steel B) were reheated to $1050{ }^{\circ} \mathrm{C}$ for $6 \mathrm{~min}, 10 \mathrm{~min}$ and 15 min, respectively. Then they were cooled in air. The influence of reheating treatment on the AlN precipitates was investigated. Fig. 4 shows the distribution of AlN precipitates. It can be found that when the reheating temperature is $1050{ }^{\circ} \mathrm{C}$, the longer the holding time is, the more the number of AlN precipitates gets. The holding time is $6 \mathrm{~min}$, their size is in the range of $0.1-1 \mu \mathrm{m}$; when the holding time is $15 \mathrm{~min}$, the number of AlN is clearly increased, and the size is evidently homogeneous. The size is concentrated in $500 \mathrm{~nm}$, meanwhile some AlN precipitate clusters appear.

The reheat treatment was carried out in order to soften the cast strips. Meanwhile the behavior of AlN precipitates during reheat treatment is important. In the reheating process, the amount of dislocations decrease, and AlN precipitates are dissolved and subsequently re-precipitated ${ }^{[19]}$. According to Ref. [2], the solid solubility product was calculated by thermodynamics as follows:

$$
\lg \{[\mathrm{Al}] \cdot[\mathrm{N}]\}_{\alpha}=2.72-10062 / T
$$

where $[\mathrm{Al}],[\mathrm{N}]$ is the equilibrium solid solubility of $\mathrm{Al}$ and $\mathrm{N}$ at the temperature of $T$, respectively. $T$ is the temperature $(\mathrm{K})$, and the matrix $\alpha$ is ferrite. Suppose $(\mathrm{Al})$ and $(\mathrm{N})$ are the mass percent of $\mathrm{Al}$ and $\mathrm{N}$ separately. When $T$ is $1323 \mathrm{~K}$, as known from the calculation: $(\mathrm{Al}) \cdot(\mathrm{N})>[\mathrm{Al}] \cdot[\mathrm{N}]$. Therefore, part of precipitated solid phases solved into the base metal, and the saturated solidification $\mathrm{Al}$ and $\mathrm{N}$ atoms under air cooling condition precipitate dispersively. According to the TTP and CCP curves in Ref. [2], AlN precipitate will be removed in between $1140{ }^{\circ} \mathrm{C}$ and $1160{ }^{\circ} \mathrm{C}$ at greatest rapidity. $1050{ }^{\circ} \mathrm{C}$ is close to the lower limit of the temperature region. So the number of AlN in- 


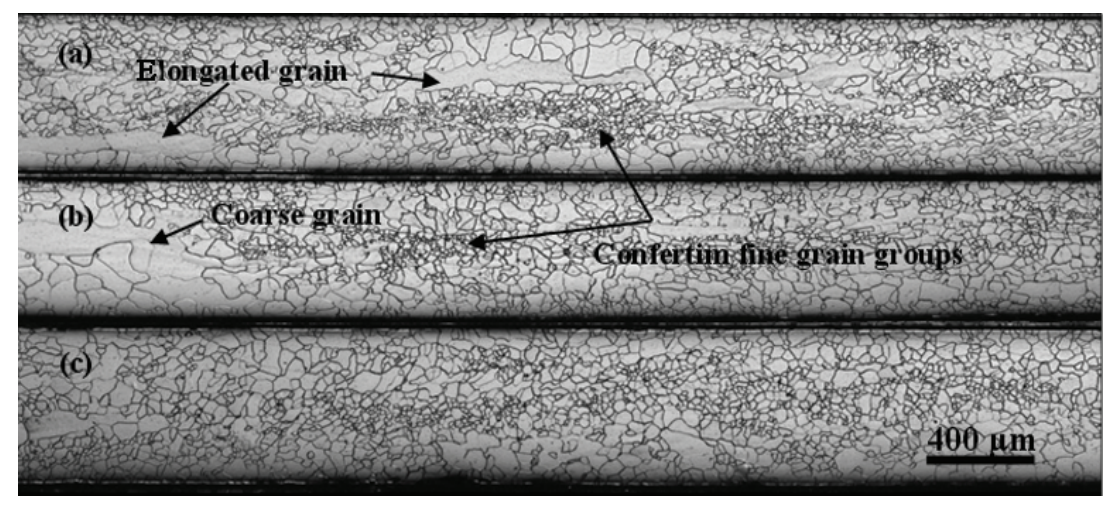

Fig. 5 The annealed microstructures of steel A (a), steel B (b) and steel C (c)

creases. When the holding time is $6 \mathrm{~min}$, the AlN precipitates are dissolved by solid solution reaction. The atomic diffusion of $\mathrm{Al}$ and $\mathrm{N}$ occurs in short distance that results in sharp concentration gradients. For this reason, the size difference of AlN is much greater. The size of AlN is in the range of $0.1-1.0 \mu \mathrm{m}$. With the increase of the holding time, the solid solubility limit of AlN in Fe increase, meanwhile, the atomic diffusion of $\mathrm{Al}$ and $\mathrm{N}$ are promoted. The atomic $\mathrm{Al}$ concentration is homogeneous in cast strips. The diameter of $\mathrm{AlN}$ is about $500 \mathrm{~nm}$. In this case, AlN can evenly precipitate, and the precipitated phases only have a little difference in size.

\subsection{Microstructure and AlN precipitates in annealed strips}

Three cold rolled non-oriented electrical steels strips with different $\mathrm{Si} / \mathrm{Al}$ ratios were annealed at $900{ }^{\circ} \mathrm{C}$ for $8 \mathrm{~min}$. The annealed microstructure is shown in Fig. 5. It was observed that the complete recrystallized microstructure exists in the nonoriented electrical steel strips. Their average grain size is about $20-40 \mu \mathrm{m}$, and this size is too small to develop the excellent magnetic properties. In addition, the microstructure becomes uniform with the increase of the $\mathrm{Si} / \mathrm{Al}$ ratio. Steel A has a large number of banded structure, intensive small grains and some coarse grains which are harmful to the magnetic properties (see Fig. 5(a)). Steel B has a small number of uneven microstructure. Among the three, the uniformity of steel $\mathrm{C}$ is the best. The inhomogeneity of the annealed microstructure might be associated with the distribution of AlN precipitation. In steel A, high aluminum content lead to multiple AlN precipitates. The recrystallization temperature significantly increased with the increase of precipitates, as a result some grains could not develop fully recrystallization and the uniform microstructure.

The iron loss of the non-oriented electrical steel is mainly dependent on the grain size. The grain size is affected by many factors such as chemical composition, initial grain size, heating rate, annealing temperature, precipitates. Under the condition of the same

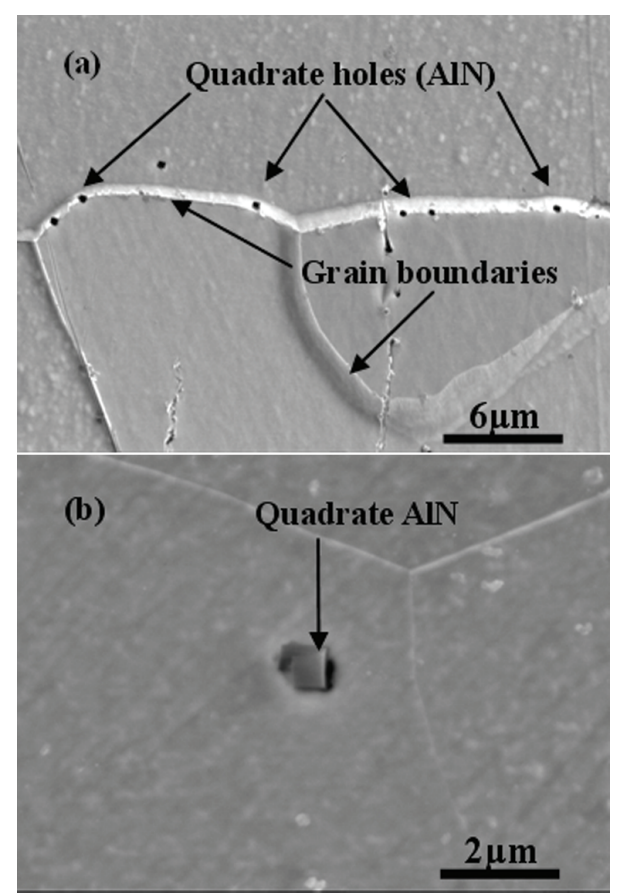

Fig. 6 SEM micrographs of AlN precipitates in annealed strips: (a) distribution position of AlN; (b) shape of AlN

annealing process, the grain sizes of these steels are not as big as we hope. One of the reasons might be high deformation rate which resulted in high nucleation rate. The other is impurity. As we all know, the second-phase particles play an important role in the non-oriented electrical steels. They can have a negative effect on the recrystallization and the magnetization behavior of the electrical steel sheets ${ }^{[20]}$. The AlN precipitates in the annealed strips are showed in Fig. 6, it can be seen that regardless of the size, distribution or number, AlN precipitates markedly hinder the movement of the grain boundaries.

\section{Conclusions}

(1) With the increase of $\mathrm{Si} / \mathrm{Al}$ ratio, the casting microstructure changes from the columnar grains to 
the equiaxed grains, at the same time, the number of AlN precipitates reduces and the distribution becomes to be dispersive.

(2) When the reheating temperature is $1050{ }^{\circ} \mathrm{C}$, with the increase of the holding time, the amount of precipitates increases and the size is uniform. The holding time prolongs to $15 \mathrm{~min}$, the second phase (AlN) precipitate in the manner of particles with uniform size. The size of these particles is about $500 \mu \mathrm{m}$. That is to say, a suitable reheat treatment may be a worth exploring way to control the AlN precipitation.

(3) The sizes of the recrystallized grains are in the range of 20-50 $\mu \mathrm{m}$. Many AlN particles are located at the grain boundaries, which hinder clearly recrystallized grains growth. Therefore, the size and distribution of AlN precipitates in annealed strips are one of the reasons for the fine grains.

\section{Acknowledgements}

This work was financially supported by the National Natural Science Foundation of China (Nos. 50734001 and $51004035)$

\section{REFERENCES}

[1] B.D. Cullity and C.D. Graham, Introduction to Magnetic Materials, John Wiley \& Sons, Hoboken, 2009, p. 440.

[2] Z.Z. He, Y. Zhao and H.W. Luo, Electrical Steels, Metallurgical Industry Press, Beijing, 2012, p. 25. (in Chinese)

[3] Y. Sato, T. Sato and Y. Okazaki, Mater. Sci. Eng. 99 (1988) 73.
[4] T. Goryczka and P. Ochin, J. Mater. Process. Technol. 162-163 (2005) 178.

[5] S. Das, N.S. Lim, J.B. Seol, H.W. Kim and C.G. Park, Mater. Des. 31 (2010) 1633.

[6] Y. Birol, J. Alloys. Compd. 458 (2008) 265.

[7] J.Y. Park, K.H. Oh and H.Y. Ra, Scr. Mater. 40 (1999) 881.

[8] E.J. Gutierrez-Castaneda and A. Salinas-Rodriguez, J. Magn. Magn. Mater. 323 (2011) 2524.

[9] S. Silva Ferreira de Dafe, S. da Costa Paolinelli and A. Barros Cota, J. Magn. Magn. Mater. 323 (2011) 3234.

[10] J.T. Park and J.A. Szpunar, Acta Mater. 51 (2003) 3037.

[11] K. Verbeken, J. Schneider, J. Verstraete, H. Hermann and Y. Houbaert, IEEE Trans. Magn. 44 (2008) 3820.

[12] H.Yu, Q.X. Chen and Y.L. Kang, Mater. Charact. 54 (2005) 347.

[13] O. Fischer and J. Schneider, J. Magn. Magn. Mater. 254-255 (2003) 302.

[14] K. Jenkins and M. Lindenmo, J. Magn. Magn. Mater. 320 (2008) 2423.

[15] T. Nakayama and N. Honjou, J. Magn. Magn. Mater. 213 (2000) 87.

[16] H.T. Liu, Z. Y. Liu, C.G. Li, G.M. Cao and G.D. Wang, Mater. Charact. 62 (2011) 463.

[17] F.J.G. Landgraf, T. Yonamine, R. Takanohashi, F.Q. Silva, J.P.V. Tosetti, F.B. Neto, E. Albertin, V.N.G. Mazzarella, I.G.S. Falleiros and M. Emura, J. Magn. Magn. Mater. 254-255 (2003) 364.

[18] A. Zaveryukha and C. Davis, Mater. Sci. Eng. A 345 (2003) 23.

[19] J.H. Oh, S.H. Cho and J.J. Jonas, ISIJ Int. 41 (2001) 484.

[20] K. Jenkins and M. Lindenmo, J. Magn. Magn. Mater. 320 (2008) 2423. 